\title{
What is the Role of OBGYN Residents during COVID-19 Pandemics?
}

\author{
Debora Farias Batista Leite ${ }^{10} \quad$ Aline Duarte Maranhão $^{1(0)}$ Elias Ferreira de Melo jr. ${ }^{1(0)}$
}

${ }^{1}$ Integrated Study Group on Gynecology and Obstetrics, Universidade Federal de Pernambuco, Recife, PE, Brazil

Rev Bras Ginecol Obstet 2020;42(10):676-678.

Address for correspondence Debora Farias Batista Leite, Avenida Prof Moraes Rego, s/n, 50740-900, Cidade Universitária, Recife, PE, Brazil (e-mail: debora.leite@ufpe.br).

Dear Editor,

We have read with great interest the Special Article from Romão et al., ${ }^{1}$ with recommendations from the Brazilian Federation of Gynecology and Obstetrics Associations (FEBRASGO, in the Portuguese acronym) regarding medical residency training during the coronavirus disease (COVID-19) pandemic. While it is clear in considering aspects of theoretical activities, it is less conclusive of how practical workload should be accomplished: can we participate in COVID-19 care while practicing obstetrics and gynecology (OBGYN)?

We agree that there are major concerns of how the COVID19 pandemic will impact the apprenticeship of the residents and, especially, women's health care. We are aware of and respectful to all the necessary arrangements in dealing with the COVID-19 pandemic. ${ }^{2}$ In Brazil, at least a third of OBGYN residents were relocated to deliver care to suspected or confirmed COVID-19 patients. ${ }^{3}$ Although it may represent OBGYN interrupted regular activities, it comes to our attention that the relocation of residents was simultaneous to important modifications in women's health care in Brazil.

First, women are afraid of seeking medical care and exposing themselves to SARS-CoV-2, therefore tending to underestimate their health condition and to delay arrival to medical facilities; they presume there is a great risk of viral infection. Second, quarantine and lockdown measures have restricted health care to essential services, decreasing access to on-time diagnosis. Health personnel were deviated from women's health facilities, including antenatal clinics, to help emergency services. Ultrasound and laboratory tests, which were never adequate, are now restricted to a bare minimum. Therefore, women are admitted to hospitals in worsened medical conditions; it seems that $10 \%$ of maternal deaths in Brazil this year are related to COVID-19. ${ }^{4}$ Third, other health issues arise during the pandemic. To cite just a few, domestic violence, anxiety, and perinatal depression are rising in times of social isolation and emotional constraints. ${ }^{5,6}$ We understand that OBGYN are the leading professionals in women's integral health care, and residents must take part on it. Finally, and of the uttermost importance, we still do not know how SARS-CoV-2 behaves in specific conditions of our field, such as in pregnancy ${ }^{7}$ or oncology. ${ }^{8}$ Therefore, we can still afford COVID-19 care while offering OBGYN care.

In our view, the role of OBGYN personnel in taking care of women's health is irreplaceable. In times of pandemics, our role is to provide a safe environment for the continuity of our species, which is not a lesser endeavor. In this context, program directors and institutions should focus the efforts of OBGYN residents on activities for which they have the best training for, and in sectors where they can really help. For example, emergency obstetrical care, which is historically overburdened in terms of resource personnel. Many lessons can be learned from the pandemic as a whole, but in our field, we have a clear picture of how essential our work really is. Antenatal care, labor wards, OBGYN emergency rooms, and gynecological oncology procedures are still places for assistance and residency training. If there is less gynecological training during the pandemic, ${ }^{3}$ residents must be replaced to obstetrics or oncology, which is in accordance with the FEBRASGO statement. ${ }^{1}$

The pervasive feeling among some institutions that OBGYN is a common specialty is unequivocally wrong. We have a unique set of abilities which are simply indispensable. Obstetrics and gynecology personnel cannot be relocated without considerable impact on the quality of care. It is a waste of precious human resources to use the OBGYN workforce in the frontline of COVID when we have pressing needs in attending obstetrics emergencies and oncologic cases. Perhaps more lives will be wasted - or an increase of long-term sequelae for both mother and newborn ${ }^{9,10}$ with this shift of personnel from where they are most effectively used to performing general COVID-19 care. Gynecological and perinatology health care must be seen as essential areas of medical assistance and education.

Residency training in 2020 has been challenging for residents, program directors, institutions and policy makers. Obstetrics and gynecology residents are skilled professionals and need to work as such. In Brazil, women's health is marked by inequalities of access and deliver of care, which impairs
DOI https://doi.org/ 10.1055/s-0040-1719110. ISSN $0100-7203$.
Copyright $\odot 2020$ by Thieme Revinter Publicações Ltda, Rio de Janeiro, Brazil

\section{License terms}

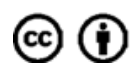


the maternal morbidity and mortality rate. Residency programs need to be in line with women's needs.

Conflict of Interests

The authors have no conflict of interests to declare.

\section{References}

1 Romão GS, Schreiner L, Laranjeiras CLS, Di Bella ZIKJ, Coelho RA, Simões MCR, et al. Medical residency in gynecology and obstetrics in times of COVID-19: recommendations of the national specialized commission on medical residency of FEBRASGO. Rev Bras Ginecol Obstet. 2020;42(07):411-414. Doi: 10.1055/s-0040-1715147

2 Ministério da Educação. Nota técnica no. 1/2020/CNRM/ CGRS/DDES/SESU/SESU. Recomendações quanto ao desenvolvimento das atividades dos Programas de Residência Médica (PRMs) durante enfrentamento à pandemia por COVID-19 [Internet]. 2020 [cited 2020 Jan 15]. Available from: http://portal.mec. gov.br/index.php?option=com_docman\&view=download\&alias=145481-sei-23000\&category_slug=2020\&Itemid=30192

3 Brito LGO, Romão GS, Fernandes CE, Silva-Filho AL. Impact of COVID-19 on Brazilian medical residencies in obstetrics and gynecology. Int J Gynaecol Obstet. 2020;150(03):411-412. Doi: 10.1002/ijgo.13283

4 Takemoto MLS, Menezes MO, Andreucci CB, Nakamura-Pereira M, Amorim MMR, Katz L, Knobel R. The tragedy of COVID-19 in Brazil: 124 maternal deaths and counting. Int J Gynaecol Obstet. 2020;151(01):154-156. Doi: 10.1002/ijgo.13300
5 Ahorsu DK, Imani V, Lin CY, Timpka T, Broström A, Updegraff JA, et al. Associations between fear of COVID-19, mental health, and preventive behaviours across pregnant women and husbands: an actor-partner interdependence modelling. Int J Ment Health Addict. 2020; **::1-15. Doi: 10.1007/s11469-020-00340-x [ahead of print]

6 Saccone G, Florio A, Aiello F, Venturella R, De Angelis MC, Locci M, et al. Psychological impact of coronavirus disease 2019 in pregnant women. Am J Obstet Gynecol. 2020;223(02):293-295. Doi: 10.1016/j.ajog.2020.05.003

7 Lamouroux A, Attie-Bitach T, Martinovic J, Leruez-Ville M, Ville Y. Evidence for and against vertical transmission for severe acute respiratory syndrome coronavirus 2. Am J Obstet Gynecol. 2020; 223(01):91.e1-91.e4. Doi: 10.1016/j.ajog.2020.04.039

8 Dai M, Liu D, Liu M, Zhou F, Li G, Chen Z, et al. Patients with cancer appear more vulnerable to SARS-CoV-2: a multicenter study during the COVID-19 outbreak. Cancer Discov. 2020;10(06): 783-791. Doi: 10.1158/2159-8290.CD-20-0422

9 Ferreira EC, Costa ML, Pacagnella RC, Silveira C, Andreucci CB, Zanardi DM, et al. General and reproductive health among women after an episode of severe maternal morbidity: Results from the COMMAG study. Int J Gynaecol Obstet. 2020;150(01):83-91. Doi: 10.1002/ijgo.13161

10 Camargo RS, Pacagnella RC, Cecatti JG, Parpinelli MA, Souza JP, Sousa MH. Subsequent reproductive outcome in women who have experienced a potentially life-threatening condition or a maternal near-miss during pregnancy. Clinics (São Paulo). 2011; 66(08):1367-1372. Doi: 10.1590/S1807-59322011000800010

\section{Authors' response}

\author{
Gustavo Salata Romão ${ }^{10}$ \\ ${ }^{1}$ Universidade de Ribeirão Preto, Ribeirão Preto, SP, Brazil
}

Dear Editor,

We are grateful to the authors for their comments about our recently published manuscript outlining the recommendations from the Brazilian Federation of Gynecology and Obstetrics Associations (FEBRASGO, in the Portuguese acronym) in medical residency training during the coronavirus disease (COVID-19) pandemic. We read with interest their comments and agree that the COVID-19 pandemic has affected both the quality of postgraduate training and the quality of care in non-COVID conditions.

The obstetrics and gynecology (ObGyn) residency training program is indeed heterogeneous, since acquisition of clinical, surgical and emergency management skills is mandatory. Daily practice, along with an adequate theoretical preparation, plays a fundamental role in achieving autonomy. Regarding the comments of the authors about the practical workload of ObGyn residents, we recommended that it should be mainly performed in time-sensitive care activities such as prenatal, childbirth, postpartum, gynecological oncology, family planning, sexually transmitted infec-
Address for correspondence

Gustavo Salata Romão, Av. Costábile Romano, 2.201, Ribeirânia, 14096-900, Ribeirão Preto, SP, Brazil

(e-mail: gsalataromao@gmail.com).).

tions and assistance for victims of sexual violence. For the activities that have been suspended or postponed during the pandemic, such as non-COVID inpatient or outpatient care and elective surgeries, decisions must be made locally between health managers and those responsible for residency programs. It includes providing proper resident supervision.

The need to move ObGyn residents to combat the COVID-19 pandemic will depend on epidemiological conditions in each region. In the largest hospital complex in South America, the Hospital das Clínicas of the School of Medicine, Universidade de São Paulo (HCFMUSP, in the Portuguese acronym), almost 500 volunteer residents from 40 different residency programs were recruited to work in the frontlines of the COVID-19 pandemic. ${ }^{11}$ All residents of this multispecialty team received personal protective equipment (PPE) and appropriate training in individual protection and orotracheal intubation, with a maximum weekly workload of 48 hours. The team of supervisors was composed of working physicians in intensive care units (ICUs), wards, and in the emergency department. A total of 132 residents of this group reported their opinions through a 
survey. Although many of them have expressed fear of becoming ill and concerns about the possible deficits in their professional training, important positive aspects were also reported, such as the quick growth in professionalism, altruism and communication in the healthcare field.

In other countries severely affected by the pandemic, such as the United States, trainees in different clinical and surgical areas have also been moved to provide care for COVID-19 patients. $^{12}$

In Brazil, medical residency is essentially time-based and not competency-based. ${ }^{13}$ Consequently, after a period of 3 years of training, the ObGyn resident is considered fit to practice, even if the quality of the training of a resident or of a group of residents has been compromised. As the competencies are not systematically assessed throughout the program, it is difficult to objectively measure the damage resulting from the lack of training during the COVID-19 pandemic.

In 2010, the Carnegie Foundation's report on the reform for postgraduate programs proposed a model with "fixed standards and flexible paths." ${ }^{14}$ This model was adopted in many countries where the readiness of the residents for unsupervised activities is formally assessed through the Entrustable Professional Activities (EPAs). ${ }^{15}$

Currently, the FEBRASGO is preparing and validating the Brazilian ObGyn EPAs, which will serve as a reference to ensure that the resident is able to carry out the activities properly without supervision, bridging the gap between well-designed competency structure and clinical practice with the patient.

\section{Note}

Text prepared by the members of the National Specialized Commission on Medical Residency and endorsed by the Scientific Board and Presidency of the Brazilian Federation of Gynecology and Obstetrics Associations (FEBRASGO).

\section{Conflict of Interests}

The authors have no conflict of interests to declare.

\section{References}

1 Baptista FVD, Aguiar MRA, Moreira JA, Sousa FCB, Plenns GCM, Simao RR, et al. Contributions of residents from multiple specializations in managing the COVID-19 pandemic in the largest public hospital Brazil. Clinics (São Paulo). 2020;75:e2229. Doi: 10.6061/ clinics/2020/e2229

2 Edigin E, Eseaton PO, Shaka H, Ojemolon PE, Asemota IR, Akuna E. Impact of COVID-19 pandemic on medical postgraduate training in the United States. Med Educ Online. 2020;25(01):1774318. Doi: 10.1080/10872981.2020.1774318

3 Romão GS, Silva de Sá MF. Competency-based training and the competency framework in gynecology and obstetrics in Brazil. Rev Bras Ginecol Obstet. 2020;42(05):272-288. Doi: 10.1055/s0040-1708887

4 Cooke M, Irby DM, O'Brien BC. Educating physicians: a call for reform of medical school and residency. San Francisco: JosseyBass; 2010

5 ten Cate O. An updated primer on Entrustable Professional Activities (EPAs). Rev Bras Educ Med. 2019;43(01):712-720. Doi: 10.1590/1981-5271v43suplemento1-20190238.ing 